\title{
Digital Technology Development: Distance Education
}

\author{
Hasanova J.V. Najafova K.A.* Karimova G.A. \\ Azerbaijan State University of Economics - UNEC, Baku, Azerbaijan \\ ${ }^{*}$ Corresponding author. Email: hasanovacemile@mail.ru
}

\begin{abstract}
In the article, the authors emphasize the use of distance educational technologies when studying at a university. Digital learning and distance teaching technologies are a very effective and promising area at the present time. The possibilities of distance learning technologies are constantly expanding due to the massive introduction of new electronic resources, the number of which continues to grow rapidly. Azerbaijan does not lag behind this process: dozens of online learning platforms are actively developing, universities and commercial structures are creating hundreds of online courses in a variety of subjects. According to experts, today's request for online courses is about 1 million citizens of Azerbaijan.
\end{abstract}

Keywords: digital environment, digitalization, educational interaction, Internet resource, priority project,

online courses, higher education

\section{INTRODUCTION}

In the modern world, the competitiveness of countries has already become a serious factor. In today's globalized world, the sustainable and sustainable development of each country requires adaptation to the principles of international competition in all spheres of society.

Today, the creation of an information society and a competitive high-tech national economy has become the main focus of public policy in several countries. In these countries, information and communication technologies (ICTs) are the most important development factor [4]. This area has a direct impact on the political, economic and social activities of states and contributes to the globalization of the economy and public relations. How the education system is built in the information society, what technologies and how it is used to modernize education, today is one of the most pressing problems.

Since the global economy today is more knowledge-based, the education systems of countries must also create a system that meets these requirements. This factor has led to a series of systematic educational reforms in developed countries.

\section{METHODS}

As mentioned above, the computerization of educational institutions creates significant changes in the education system. It is noteworthy that information technology is widely used not only in the management of educational institutions but also in the implementation of extracurricular activities. In particular, the advent of the Internet, its popularity among young people, and new horizons are opening up in many different fields of education. There is no technical knowledge in training that can be compared with didactic abilities [2].
With the rapid growth of information, the requirements for the content and organization of education are also changing. Education on this day should teach students not to memorize a lot, but to learn to solve problems critically and effectively, independently. From this point of view, a scientific and methodological study of the problems of increasing the cognitive activity of students in the educational process is more relevant. The specificity of mathematics requires the use of information and communication technologies in the educational process, as well as the systematic use of methods and techniques that improve cognitive functions in the learning process.

The use of multimedia tools in the educational process also requires training. Multimedia equipment combines the three most important components in the body as an important didactic tool: the content of the educational material, its interpretation method, and teaching methodology.

These components are closely related to each other, creating a learning system, a person

provides a comprehensive opportunity for the implementation of the process of studying ozone [6].

Information resources are divided into two groups: information contained in the student's computer (local component) and information (network component) on the computers of the training center. Depending on the way information is posted, the technology for creating and using these resources must meet certain requirements. The local component is a product stub, a magnetic tape audio cassette, and computer media [16].

The ability of the information resources used in training is appropriate requires the use of an information carrier. For this reason, CDROM technologies are used for multimedia courses. An interactive multimedia course allows you to synthesize various multimedia environments (text, static 
and dynamic graphics, audio and video), turning the student into an active participant in the educational process (each new block of information presented by the student is selected by the computer in accordance with its previous activity and level of development). The third principle of creating ETV is a multimedia presentation of educational material.

It is mainly used for teaching materials. Various HTML editors are used to create educational material in the form of an Internet resource. This makes the HTML document interactive and allows to host information on the server. When providing online training materials, it should be borne in mind that online communication with the server can cause certain technical problems due to the poor quality of telecommunication channels, the effectiveness of training can be reduced, as a result of which the Internet can adversely affect education, e-learning, and ICT. To avoid such problems, the teacher must take certain preventive measures in advance. The programming systems used to create a local component usually provide access to Internet resources in a multimedia course (marking specific names on the Internet), which leads to a unified network of information and educational resources (in the narrow sense) [2].

Classification of ETV with educational institutions. The content of any educational material (using any educational technology) is complex and reflects the necessary and sufficient level of knowledge and skills that the student must master. The content of the ETV with the curriculum should be compiled in accordance with state standards and modern training technologies. The training material should be structured so that the individual can form his own knowledge of scientific and subjective knowledge and develop the skills of their application [3].

\section{RESULTS}

E-mail can also create virtual educational groups in terms of didactics and asynchronous exchange of information with members of this group.

It is possible to transfer and receive large files, databases, electronic documents by e-mail. Anyone who knows a few simple commands to work on a computer can use this most popular Internet service. E-mail provides both students and students with the best opportunities for better preparation for lessons, discussion and decision-making with other participants, monitoring the implementation of decisions and searching for information stored on FTP-servers. Receive lecture texts from remote lecturers using the email service, participate in these lectures online, attend seminars and workshops, and much more. There is [14].

Electronic conferences, often referred to as computer conferences, are Internet services that allow remote participants to discuss, make decisions and jointly control decisions made. In this case, the conference participants must be online simultaneously on the computer. The workplace equipment of concierge participants is largely the same as the workplace equipment of email users. However, the use of projectors offers great opportunities for more effective organization of electronic conferences. The software used to organize the conference should be the same for all users. One of the most popular programs that support electronic conference mode is Skype. This software offers great opportunities for building multimedia communications between users [13].

Participants in electronic conferences are time-dependent (a synchronous form of training). The main feature of electronic conferences is that the audio, video and written information provided for 1 participant is accepted simultaneously by all participants, and their answers are simultaneously accepted by all participants. The Internet is a great way to create virtual study groups and ensure their participation in lectures, seminars, and workshops based on a well-known class schedule. The presence of email participants, that is, the opportunity to fully utilize the benefits of email services, is a prerequisite.

To organize electronic conferences on a local computer network, it is important to provide the network with an FTP server. Such a server contains information intended for all conference participants and provides participants with ample opportunities to use this information. Unlike email mode, the information provided to conference participants is open to all conference participants [14]. Text, graphics, audio and video, etc. The ability to deliver information to users (members of virtual groups), as well as instructions for using this information, is a didactic feature of this type of service.

\section{Teleconferencing and video telephony services}

These tools provide two-way communication for both students and teachers. Despite the fact that there are currently many participants, only two users can share information at a time. Other participants are only observers until they are given this opportunity. Although the hardware and software for organizing this type of service differs in its specificity, it is mainly compatible with the hardware and software of electronic conferences. The most important thing that distinguishes teleconferencing and video conferencing from other Internet services is the limitation of the amount of information transmitted and received by participants, and the fact that these restrictions also affect the quality of the material [8].

Network services of this type are parallel to the didactic functions of network services with images, sound and graphic information. A wide range of options for real-time delivery to users during a session. These features provide excellent opportunities for live listening to lectures, seminars, consultations, exams and examinations in ways close to traditional methods.

\section{E-libraries}

Digital libraries have books, internal orders and instructions, various instructions and instructions. Database management systems, which are stored in an organized form, are stored in electronic documents provided by the navigation and search system. An electronic library can also be prepared in the form of a web page that contains various electronic information (literature, etc., computer programs, multimedia, and audio-video files). These types of electronic databases can 
be created in the form of both universal and separate specialized databases [7].

The creation and widespread use of electronic libraries should be focused primarily on the creation of new libraries based on the new requirements of traditional libraries operating in educational institutions. The availability of broadband Internet services is also an important factor in the creation and use of electronic libraries.

The introduction of an e-library makes it possible to obtain more complete, accurate and timely information about library resources. Using the services of the electronic library, the user receives specific answers to specific requests, which, first of all, helps prevent time loss. If the work of the electronic library is organized on the network and, in particular, on the global network, the effect can be increased many times [1].

The use of electronic libraries opens up great opportunities for the effective organization of the educational process, and the use of automated library search and navigation systems creates good conditions for both students and teachers, as well as for other participants in the educational process.

Today, the largest electronic library in the world operates in the People's Republic of China. The library contains a database of 12 million various electronic documents. Access to the library is via the Internet. The most interesting aspect of the library is that piracy (theft) is not practiced here. More precisely, the book occupies a very important place in copyright protection [15].

\section{DISCUSSION}

Today, the development of ICT applications in education goes on in two directions:

1. The use of ICTs to improve the quality of traditional forms of education and improve the quality of education.

2. The development of new methods in the educational process and the introduction of distance learning technologies using new methods.

In recent years, the form of distance education has undergone global changes in the field of education and information culture and is now becoming the main form of education in developed countries. The development of distance education forms an incentive for the creation of new educational institutions and faculties, and this will lead to a rapid increase in the number of those who seek education in this form, and, consequently, to additional new costs for education. However, the experience of world universities, already transferred to the distance education system, proves that this form of financing the education system is justified and provides a good basis for additional income [9].

The development of distance learning is accelerated by the creation of personal computers and the Internet and is currently becoming the most popular form of learning. The following are the main characteristics of distance learning: 1. Expanding educational opportunities for the population. For example, if time constraints limit the traditional activities of participants in a traditional way, these restrictions are almost completely eliminated during distance learning.

2. Providing radically completed transfers of information in new forms and contents: for example, the widespread use of multimedia systems in educational activities, the provision of non-standard information, the use of largescale automated examination systems (electronic library services, electronic conferences, etc.) .

3. Expanding opportunities for a more in-depth assessment of the knowledge, application of test technologies and analysis of results using analytical systems, etc. [10].

Distance education institutions can be divided:

- Only educational institutions are engaged in distance education. There are not many educational institutions in this sector, and educational institutions of this form are more common in the United States.

- Enterprises are working on improving and retraining specialists. Currently, there are many educational institutions in the world that are engaged in this type of activity, and they prefer to conduct their activities at a distance. Many of the world's leading universities have faculties or continuing education courses. The distance learning method provides excellent opportunities for the flexible creation of such mobile groups and the effective organization of work with them, which opens up great opportunities for work both for representatives of the virtual group and those involved in its training. It should be noted that most distance learning institutions are based on orders from students to organize improvement and retraining, which ultimately leads to a good result.

- At the same time, educational institutions that provide both traditional and distance education: at present, almost all the leading universities in the world use the form of distance learning, and the subcontractors involved in this type of education are called objects of open education. The successful organization of open faculties provides excellent opportunities for additional income and dividends, more than anything else [11].

\section{CONCLUSION}

Based on the characteristics of distance learning, the following applies:

1. The structural features of the course are that distance learning does not require the student to write lecture texts or other electronic educational materials. The student can archive all the proposed materials on the storage device that they use, and be able to read and read this material on the monitor at any time, anytime, anywhere. Much depends on the work of the developers of the course material here. Text and materials should be designed in such a way that they are not tiring and attractive. For this purpose, it is advisable to use the capabilities of custom design and presentation software. It is important to make the course as simple and straightforward as possible.

2. Means of communication. The use of distance learning technology requires specialized hardware and software to deliver information, data and other educational materials 
Equilibrium Approach with Endogenous Growth, Munich Personal RePEc Archive, 17819.

These may include computer kits, printers, scanners, projectors, modems, telephones, televisions, faxes and other network devices and software that can ensure the normal operation of these devices and access to the didactic capabilities of the Internet. In addition, the capabilities of the communication environment must be consistent with the learning environment.

Relationships with student support. As is the case with traditional forms of learning, distance learning is enriched with various teaching methods. The main goal of these methods and the most important (almost certainly the biggest problem) of their tasks is to build close relations between pupils and students in this virtual group. Despite the fact that some work has been done in this area and tools have been developed (crack, electronic, audio and video conferencing, etc.) [12]. It is still necessary to perform certain actions (for example, based on the psychological state of training, etc.).

\section{REFERENCES}

[1] Davidson, R., Mackinnon, J. G. (1993). "Estimation and Inference in Econometrics". Oxford: Oxford University Press.

[2] Dickey, D., Fuller, W. (1981). Likelihood Ratio Statistics for Autoregressive Time Series with a Unit Root. Econometrica: Journal of the Econometric Society, 49(4), 1057-72

[3] Falk, Martin (2007), "R\&D spending in the hightech sector and economic growth", Research in Economics, 61 (2007), s.140-147

[4] Institutional Settings and the Source of Funds of R\&D Matter?", Oxford Bulletin Of Economics And Statistics, 66, 3 (2004), s.0305-9049

[5] Hasanova J.V. (2019) The transformation of human needs in the digital economy. AEBMR-Advances in Economics Business and Management Research T: 81 p. $753-756$

[6] Jones, C. I. ve Williams, J. C. (2000). Too Much of a Good Thing? The Economics of Investment in R\&D, Journal of Economic Growth, 5 (1), 65-85

[7] Jalil, Abdul ve Syed Mahmud (2009), "Environment Kuznets curve for $\mathrm{CO} 2$ emissions: A cointegration analysis for China”, Energy Policy, 37, 5167-5172.

[8] Griliches, Z. ed., R\&D, Patents and Productivity, Chicago of University Press, Chicago, 1984.

[9] Miroslav, V., Boris, M. ve Mitja, C. (2009). R\&D and Economic Growth in Slovenia: A Dynamic General
[10] Nelson, C. R., Plosser, C. R. (1982). Trends and Random Walks in Macroeconmic Time Series, Journal of Monetary Economics, 10(2), 139-162. http://doi.org/10.1016/0304-3932(82)90012-5

[11] Phillips, P. S. B., Perron, P. (1988). Testing for a Unit Root in Time Series Regression. Biometrika, 75(2), 335-346

[12] Samimi, A.J. ve S.M. Alerasoul (2009), "R\&D and Economic Growth: New Evidence from Some Developing Countries", Australian Journal of Basic and Applied Sciences, 3(4), ISSN 1991-8178, s.3464-3469.

[13] Samimi, Babanejad (2010) ICT and Economic Growth: New Evidence from Some Developing Countries Australian Journal of Basic and Applied Sciences, 4(8): 3086-3091, 2010 ISSN 1991-8178

[14] Shefer, D. ve Frenkel, A. (2005). R\&D, Firm Size and Innovation: An Empirical Analysis, Technovation, 25 (1),25-32.

[15] Wang, Eric C. (2007), "R\&D Efficiency and Economic Performance: A Cross-Country Analysis Using The Stochastic Frontier Approach", Journal of Policy Modeling, Vol. 29 (2), s.345-360.

[16] Zachariadis, Marios (2004), "R\&D-induced Growth in the OECD?", Review of Development Economics, Vol. 8 (3), s.423-439. 